\title{
Replacing Missing Teeth with Dental Implants in Pubescent Patients-A Case Report
}

\author{
Wendy C. W. Wang, Loana Tovar Suinaga, Klenise S. Paranhos, Sang-Choon Cho \\ Ashman Department of Periodontology and Implant Dentistry, New York University College of Dentistry, New \\ York, USA \\ Email: wcw251@nyu.edu
}

Received 1 June 2015; accepted 24 August 2015; published 27 August 2015

Copyright (C) 2015 by authors and Scientific Research Publishing Inc.

This work is licensed under the Creative Commons Attribution International License (CC BY). http://creativecommons.org/licenses/by/4.0/

c) (i) Open Access

\section{Abstract}

Tooth loss due to traumatic dental injury or congenital absence can cause functional and socialpsychological consequences in youth. Pubescent children with missing teeth are often targets for school bullying. The treatment modality chosen can impact their well-being during their formative years. Despite the high success rate in adult patients, implant placement in young patients is not common due to its ankylosed nature and concerns with possible infra-occlusion in the future. However, skeletal growth and remodeling is a continuous process throughout life and postponement of dental implant placement does not necessary prevent future complication or need for replacement. Dental implant placement should be considered as a viable treatment option for pubescent patients if all other conventional alternatives fail to alleviate patients' concerns both functionally and psychologically. This case report evaluates the considerations required to place dental implants in pubescent patients, as well as its advantages and disadvantages.

\section{Keywords}

Dental Implants, Pubescent, Social-Psychological, Bullying

\section{Introduction}

Tooth loss due to traumatic dental injury or congenital absence is a common and significant problem in youth [1]-[3]. Not only does it cause functional impairment, it may also lead to social-psychological consequences [3] [4]. Missing teeth in young patients has been shown to have a negative impact on their emotional status, social relationship, speaking, smiling and carrying out work [3]. 
A National Center for Education Statistics (NCES) survey (2009) showed that one third of teens reported being bullied while at school; about twenty percent of teens had been made fun because of their physical appearance [5]. Several studies have looked at the impact of dento-facial features on bullying in schools [6] [7]. Dental features have been found to be targets for nicknames, harassment, and teasing among schoolchildren [6] [7]. Moreover, comments about teeth were received more negatively than comments regarding other physical features [6]. The dento-facial features most commonly bullied were found to be spaced or missing teeth, shape and color of teeth, and prominent maxillary anterior teeth [8].

Furthermore, the treatment modality chosen has an impact on the quality of life of the young patient [3]. Often times, a removable prosthesis is prescribed for its ease of construction and low cost, however its removable naturemay not be welcomed by the patient [3]. A resin-bonded bridge may be recommended as a long-term interim prosthesis to replace the missing tooth. It is a conservative method and has been reported to have good survival rates but debonding can be a concern [9].

Dental implant placement to replace missing teeth has been documented to be a predictable treatment modality with high success rates [10] [11]. For adult patients, the use of osseointegrated dental implants is often the treatment of choice due to their independence from adjacent teeth, which are spared for preparation as bridge abutments. However, implant placement in young patients involves risks due to the "ankylosed" nature of the implant. As a result, the implant does not follow the dento-alveolar development. This nature could lead to infra-occlusion of the ankylosed implant with potential periodontal, occlusal and esthetic consequences in the future [12]-[14]. On the other hand, studies have demonstrated that alveolar remodeling and growth does not cease at puberty and vertical discrepancy between a single dental implant and its adjacent natural teeth continue to occur in adulthood [15] [16]. Therefore, postponement of dental implant placement in young patients does not necessarily exclude further complication.

The use of dental implant in pubescent patients can offer both functional and psychological benefits. The ankylosed implant is fixed into the alveolar bone and therefore feels more natural to the patient. Most importantly, the security offered by a fixed prosthesis has tremendous psychological benefits for the patient.

\section{Case Report}

A 14-year-old Asian American boy accompanied by his mother was referred to the private clinic in December 2011. The patient was healthy with unremarkable medical history. Clinical examination revealed a congenitally missing maxillary left lateral incisor (tooth \#10). The patient had been receiving orthodontic treatment to redistribute his spaces and had been wearing a removable partial denture to replace the missing tooth (Figure 1).

The patient appeared withdrawn and uninvolved during the initial clinical examination. It was disclosed that the patient had been subjected to repeated bullying in school for his missing tooth and inability to pronounce certain words. The removable prosthesis required frequent removal for cleaning after food consumption and he was often teased for the act. The lack of psychological security of the denture also prevented the patient from participating in active sports in fear of denture swallowing or dislodgement, which further isolated him from his peers. The combination of verbal bullying and isolation has led to a negative impact on his academic achievement and interest in attending school. Following discussion of the various treatment options available and risks involved, both the patient and his mother felt that a more permanent solution to replace his missing tooth was the best option to improve the patient's self-esteem and social confidence.

A root form titanium dental implant (EBI Inc., Kyungsan, South Korea) of $3.25 \mathrm{~mm}$ in diameter and $13 \mathrm{~mm}$ in length was inserted under local anesthesia in a two-stage surgical procedure. After crestal and sulcular incisions of the adjacent teeth, a full-thickness flap was reflected to expose the alveolar bone. The drilling protocol was performed according to the manufacturer's specification. Primary stability of $35 \mathrm{~N}$ cm was achieved and a cover screw was placed (Figure 2). The implant was uncovered following three months of undisturbed healing and animplant-supported porcelain fused to metal crown was delivered (Figure 3). The patient was followed up for three years and no apparent vertical discrepancy between his implant and natural teeth were noted despite his skeletal growth. The patient reported a positive psychosocial consequence following the implant restoration.

\section{Discussion}

Bullying is a common experience for many children and adolescents and its prevalence is highest during middle 


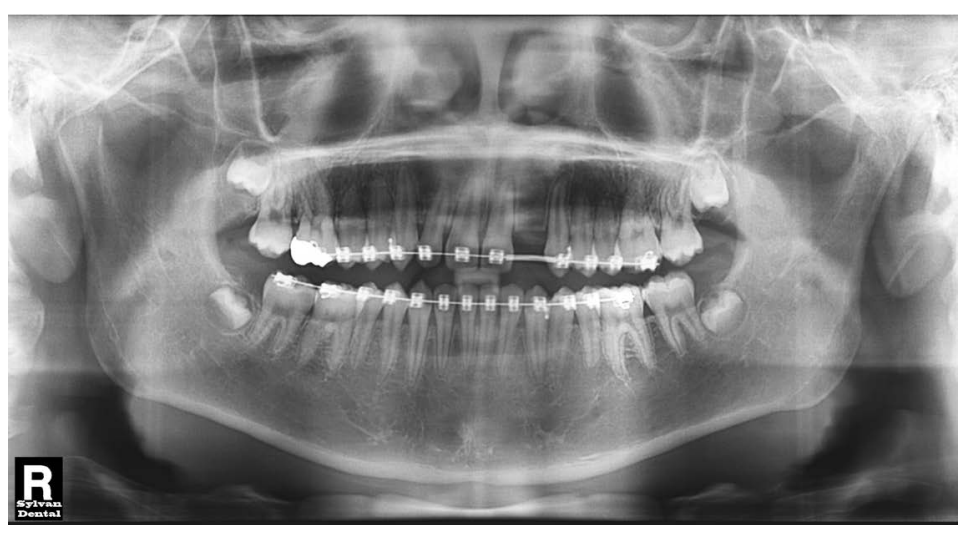

Figure 1. An orthopantomogram showing orthodontic redistribution.

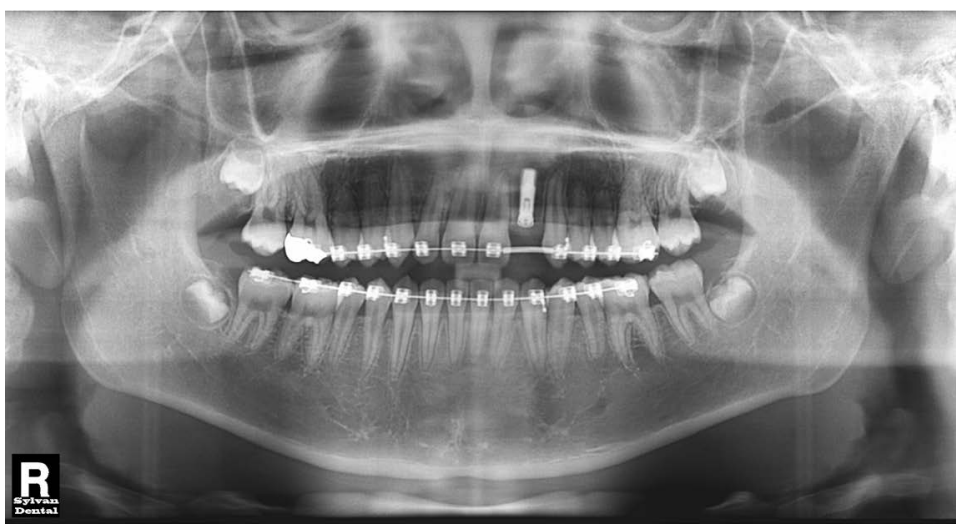

Figure 2. An orthopantomogram showing a titanium implant placed at \#10 site at the time of implant placement.

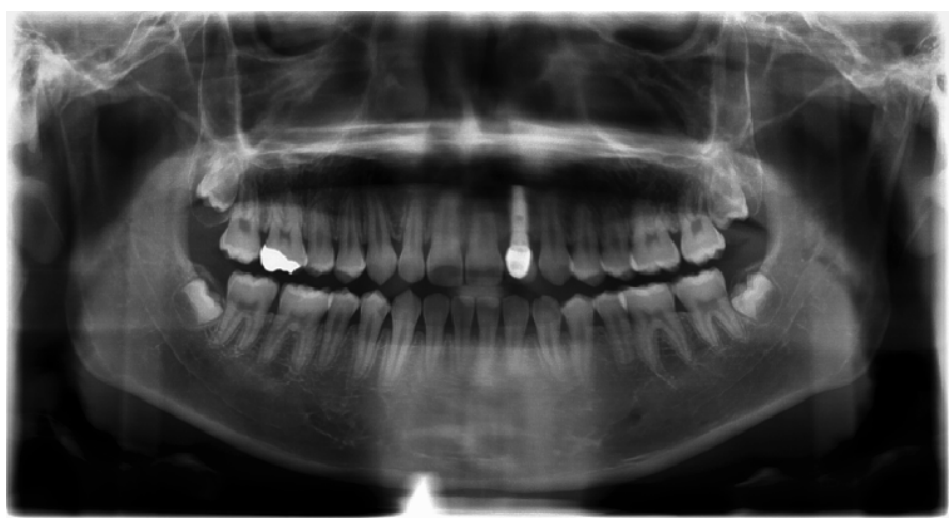

Figure 3. An orthopantomogram showing the definitive restoration.

schools [17]-[19]. General physical characteristics and dento-facial features are often reasons for social withdrawal and targets of bullying [3] [6]. The implications of bullying are extensive, and victims experience real suffering that can interfere with their social and emotional development. Studies have found links between bullying and depression, low self-esteem, contemplation of suicide, physical health problems, and poor academic performance [20]-[23].

Reservation regarding implant placement in growing patients are related to concerns over the ankylosed implant in developing dento-alveolar complex and its possible long-term sequelae. Oesterle et al. proposed that ankylosed implants placed in the posterior maxilla in children might become buried whereas implants in the an- 
terior maxilla might be lost because of resorption in the infra-dental fossa and the nasal floor [13]. Cronin et al. warned that implants placed in the posterior mandible might become submerged in patients with rotational growth of the mandible [12]. It has been suggested implant placement should be delayed until the skeletal maturation has reached [12]-[14].

Despite the hesitation, implant placement in adolescent has the advantages of maintaining the alveolar bone and faster healing potentials [24] [25]. Ledermann et al. reported positive outcomes on 42 endosseous dental implants placed in 34 patients aged 9 to 18 years [25]. Brugnolo et al. placed single dental implants in the anterior maxilla in patients aged 11.5 to 13 years and followed up for a period of 2.5 to 4.5 years. Infra-occlusion position relative to adjacent teeth was observed and modification of the restoration was needed [26]. The authors pointed out the possible long-termimplication on the mucogingival health and the need for future corrective tissue procedures [26]. In an 8 year follow up study, Thilander et al. detected that infra-occlusion of maxillary anterior single implant was more severe in patients without stable incisal relationships, and suggested orthodontic alignment for stable occlusion prior to implant placement in young patients [27]. Thilander et al. also observed that a fixed chronological age or dental stage of fully erupted permanent teeth and skeletal maturation were not sufficient to avoid infra-occlusion of the implant-supported crown due to a slight continuous eruption of the adjacent teeth occurring in post adolescence [27].

Studies have suggested that delaying dental implant placement until the patient has reached the skeletal maturity would provide a better dental treatment outcome. However, in a retrospective study, Bernard et al. showed that mature adults could also exhibit vertical discrepancy after anterior restorations with osseointegrated implants to the same extent as adolescents with residual growth potential [15]. Jemt et al. concurred the findings and demonstrated tooth movements adjacent to single-implant restorations after more than 15 years of follow-up in adult patients. Therefore, postponing dental implant placement in young patients till skeletal maturity does not negate the possible need for future prosthetic modification or implant replacement. Furthermore, the social/ psychological implication of the postponement in patients in their formative years should be explored. Clinicians must weigh the balance between the perceived ideal treatment to the need and the outcome gain of the patient. Krant suggested that the placement of implants in the anterior maxillary quadrant in young patients should only be attempted for unique treatment goals and with emphasis on the skeletal age, informed consent, and the possibility of future implant replacement [28].

With better understanding of osseointegration and improved dental implant technology, explanation and replacement of implants are no longer uncommon in the practice of implant dentistry. Treatment planning should take the patient's social psychological being into consideration and not based the decision solely on the cessation of skeletal growth. Implant treatment should be considered as a viable treatment option in young adults.

\section{Conclusion}

Dental implant placement can be the treatment of choice for pubescent patients if all other conventional alternatives fail to alleviate the patient's concerns both functionally and psychologically. The patient's growth pattern, individual status of the existing dentition, the functional status of mastication and phonetics, esthetic aspects, and emotional and psychological well-being are all factors that should be taken into consideration. Clinicians should consider future implant replacement rather than treatment postponement in patients who can benefit from the treatment modality.

\section{References}

[1] Cortes, M.I., Marcenes, W. and Sheiham, A. (2001) Prevalence and Correlates of Traumatic Injuries to the Permanent Teeth of School-Children Aged 9 - 14 Years in Belo Horizonte, Brazil. Dental Traumatology, 17, 22-26. http://dx.doi.org/10.1034/j.1600-9657.2001.170105.x

[2] Glendor, U. (2009) Aetiology and Risk Factors Related to Traumatic Dental Injuries-A Review of the Literature. Dental Traumatology, 25, 19-31. http://dx.doi.org/10.1111/j.1600-9657.2008.00694.x

[3] Hvaring, C.L., Birkeland, K. and Åstrøm, A.N. (2014) Discriminative Ability of the Generic and Condition Specific Oral Impact on Daily Performance (OIDP) among Adolescents with and without Hypodontia. BMC Oral Health, 14, 57. http://dx.doi.org/10.1186/1472-6831-14-57

[4] Cortes, M.I., Marcenes, W. and Sheiham, A. (2002) Impact of Traumatic Injuries to the Permanent Teeth on the Oral Health-Related Quality of Life in 12-14-Year-Old Children. Community Dentistry and Oral Epidemiology, 30, 193-198. 
http://dx.doi.org/10.1034/j.1600-0528.2002.300305.x

[5] National Center for Education Statistics and Bureau of Justice Statistics. Indicators of School Crime and Safety, 2009.

[6] Shaw, W.C., Meek, S.C. and Jones, D.S. (1980) Nicknames, Teasing, Harassment and the Salience of Dental Features among School Children. British Journal of Orthodontics, 7, 75-80. http://dx.doi.org/10.1179/bjo.7.2.75

[7] Seehra, J., Fleming, P.S., Newton, T. and DiBiase, A.T. (2011) Bullying in Orthodontic Patients and Its Relationship to Malocclusion, Self-Esteem and Oral Health-Related Quality of Life. Journal of Orthodontics, 38, 247-56. http://dx.doi.org/10.1179/14653121141641

[8] Al-Bitar, Z.B., Al-Omari, I.K., Sonbol, H.N., Al-Ahmad, H.T. and Cunningham, S.J. (2013) Bullying among Jordanian Schoolchildren, Its Effects on School Performance, and the Contribution of General Physical and Dentofacial Features. American Journal of Orthodontics and Dentofacial Orthopedics, 144, 872-878. http://dx.doi.org/10.1016/j.ajodo.2013.08.016

[9] Djemal, S., Setchell, D., King, P. and Wickens, J. (1999) Long-Term Survival Characteristics of 832 Resin-Retained Bridges and Splints Provided in a Post-Graduate Teaching Hospital between 1978 and 1993. Journal of Oral Rehabilitation, 26, 302-320. http://dx.doi.org/10.1046/j.1365-2842.1999.00374.x

[10] Adell, R., Lekholm, U., Rockler, B. and Brånemark, P.I. (1981) A 15-Year Study of Osseointegrated Implants in the Treatment of the Edentulous Jaw. International Journal of Oral Surgery, 10, 387-416. http://dx.doi.org/10.1016/S0300-9785(81)80077-4

[11] Buser, D., Mericske-Stern, R., Bernard, J.P., et al. (1997) Long-Term Evaluation of Non-Submerged ITI Implants. Part 1: 8-Year Life Table Analysis of a Prospective Multi-Center Study with 2359 Implants. Clinical Oral Implants Research, 8, 161-172. http://dx.doi.org/10.1034/j.1600-0501.1997.080302.x

[12] Cronin, R.J., Oesterle, L.J. and Ranly, D.M. (1994) Mandibular Implants and the Growing Patient. The International Journal of Oral \& Maxillofacial Implants, 9, 55-62.

[13] Oesterle, L.J., Cronin, R.J. and Ranly, D.M. (1993) Maxillary Implants and the Growing Patient. The International Journal of Oral \& Maxillofacial Implants, 8, 377-387.

[14] Thilander, B., Odman, J., Grondahl, K. and Friberg B. (1994) Osseointegrated Implants in Adolescents. An Alternative in Replacing Missing Teeth? European Journal of Orthodontics, 16, 84-95. http://dx.doi.org/10.1093/ejo/16.2.84

[15] Bernard, J.P., Schatz, J.P., Christou, P., Belser, U. and Kiliaridis, S. (2004) Long-Term Vertical Changes of the Anterior Maxillary Teeth Adjacent to Single Implants in Young and Mature Adults. A Retrospective Study. Journal of Clinical Periodontology, 31, 1024-1028. http://dx.doi.org/10.1111/j.1600-051X.2004.00574.X

[16] Jemt, T., Ahlberg, G., Henriksson, K. and Bondevik, O. (2006) Tooth Movements Adjacent to Single-Implant Restorations after More than 15 Years of Follow-Up. The International Journal of Prosthodontics, 20, 626-632.

[17] Carney, A.G. and Merrell, K.W. (2001) Perspectives on Understanding and Preventing an International Problem. School Psychology International, 22, 364-382. http://dx.doi.org/10.1177/0143034301223011

[18] Spriggs, A.L., Iannotti, R.J., Nansel, T.R. and Haynie, D.L. (2007) Adolescent Bullying Involvement and Perceived Family Peer and School Relations: Commonalities and Differences across Race/Ethnicity. Journal of Adolescent Health, 41, 283-293. http://dx.doi.org/10.1016/j.jadohealth.2007.04.009

[19] (2011) American Academy of Child and Adolescent Psychiatry, Bullying No. 80.

[20] Pellegrini, A.D. (1998) Bullied and Victims in School: A Review and Call for Research. Journal of Applied Developmental Psychology, 19, 156-176. http://dx.doi.org/10.1016/S0193-3973(99)80034-3

[21] Analitis, F., Velderman, M.K., Ravens-Sieberer, U., Detmar, S., Erhart, M., Herdman, M., et al. (2009) European Kidscreen Group. Being Bullied: Associated Factors in Children and Adolescents 8 to 18 Years Old in 11 European Countries. Pediatrics, 123, 569-577. http://dx.doi.org/10.1542/peds.2008-0323

[22] Kumpulainen, K. and Rasanen, E. (2000) Children Involved in Bullying at Elementary School Age: Their Psychiatric Symptoms and Deviance in Adolescence. An Epidemiological Sample. Child Abuse \& Neglect, 24, 1567-1577. http://dx.doi.org/10.1016/S0145-2134(00)00210-6

[23] Hawker, D.S. and Boulton, M.J. (2000) Twenty Years’ Research on Peer Victimization and Psychosocial Maladjustment: A Meta-Analytic Review of Cross-Sectional Studies. Journal of Child Psychology and Psychiatry, 41, 441-455. http://dx.doi.org/10.1111/1469-7610.00629

[24] Mehrali, M.C., Baraoidan, M. and Cranin, A.N. (1994) Use of Endosseous Implants in Treatment of Adolescent Trauma Patients. The New York State Dental Journal, 60, 25-29.

[25] Ledermann, P.D., Hassel, T.M. and Hefti, A.F. (1993) Osseointegrated Dental Implants as Alternative Therapy to Bridge Construction or Orthodontics in Young Patients: Seven Years of Clinical Experience. Journal of Pediatric Dentistry, 15, 327-332. 
[26] Brugnolo, E., Mazzocco, C., Cordioli, G. and Majzoub, Z. (1996) Clinical and Radiographic Findings Following Placement of Single Tooth Implants in Young Patients-Case Reports. International Journal of Periodontics \& Restorative Dentistry, 16, 421-433.

[27] Thilander, B., Ödman, J. and Jemt, T. (1999) Single Implants in the Upper Incisor Region and Their Relationship to the Adjacent Teeth. An 8-Year Follow-Up Study. Clinical Oral Implants Research, 10, 346-355. http://dx.doi.org/10.1034/j.1600-0501.1999.100502.x

[28] Kraut, R.A. (1996) Dental Implants for Children: Creating Smiles for Children without Teeth. Practical Periodontics \& Aesthetic Dentistry, 8, 909-813. 